\title{
Predictors of female sexual dysfunction: a systematic review and qualitative analysis through gender inequality paradigms
}

\author{
Megan McCool-Myers ${ }^{1 *} \mathbb{D}$, Melissa Theurich ${ }^{2} \mathbb{D}$, Andrea Zuelke ${ }^{3}$, Helge Knuettel ${ }^{4}$ and Christian Apfelbacher $^{1}$ (D)
}

\begin{abstract}
Background: Female sexual dysfunction affects $41 \%$ of reproductive-age women worldwide, making it a highly prevalent medical issue. Predictors of female sexual dysfunction are multifaceted and vary from country to country. A synthesis of potential risk factors and protective factors may aid healthcare practitioners in identifying populations at risk, in addition to revealing modifiable factors to prevent sexual dysfunction among reproductive-age women.
\end{abstract}

Methods: Observational studies which assessed the prevalence and predictors of female sexual dysfunction in reproductive-age women were systematically sought in relevant databases (2000-2014). Significant predictors were extracted from each included publication. A qualitative analysis of predictors was performed with a focus on types of sexual regimes and level of human development.

Results: One hundred thirty-five studies from 41 countries were included in the systematic review. The types of predictors varied according to the location of the study, the type of sexual regime and the level of gender inequality in that country/region. Consistently significant risk factors of female sexual dysfunction were: poor physical health, poor mental health, stress, abortion, genitourinary problems, female genital mutilation, relationship dissatisfaction, sexual abuse, and being religious. Consistently significant protective factors included: older age at marriage, exercising, daily affection, intimate communication, having a positive body image, and sex education. Some factors however had an unclear effect: age, education, employment, parity, being in a relationship, frequency of sexual intercourse, race, alcohol consumption, smoking and masturbation.

Conclusions: The sexual and reproductive lives of women are highly impacted by female sexual dysfunction, and a number of biological, psychological and social factors play a role in the prevalence of sexual dysfunction. Healthcare professionals who work with women should be aware of the many risk factors for reproductive-age women. Future prevention strategies should aim to address modifiable factors, e.g. physical activity and access to sex education; international efforts in empowering women should continue.

Keywords: Female sexual dysfunction, Female sexual disorders, Premenopausal, Reproductive-age, Prevalence, Predictors, Risk factors, Gender inequality, Narrative synthesis

\footnotetext{
* Correspondence: megan.mccool@ukr.de

${ }^{1}$ Medical Sociology, Department of Epidemiology and Preventive Medicine,

University of Regensburg, Dr. Gessler Strasse 17, 93051 Regensburg, Germany

Full list of author information is available at the end of the article
}

(c) The Author(s). 2018 Open Access This article is distributed under the terms of the Creative Commons Attribution 4.0 International License (http://creativecommons.org/licenses/by/4.0/), which permits unrestricted use, distribution, and reproduction in any medium, provided you give appropriate credit to the original author(s) and the source, provide a link to the Creative Commons license, and indicate if changes were made. The Creative Commons Public Domain Dedication waiver (http://creativecommons.org/publicdomain/zero/1.0/) applies to the data made available in this article, unless otherwise stated. 


\section{Background}

Female sexual dysfunction affects $41 \%$ of reproductive-age women worldwide, making it a highly prevalent medical issue [1]. According to the Diagnostic and Statistical Manual for Mental Disorders (5th edition, 2013), female sexual dysfunction entails the following disorders: sexual interest/arousal disorder, female orgasmic disorder and genitopelvic pain/penetration disorder [2].

Sexual dysfunction has a biopsychosocial etiology, i.e. the origin of the dysfunction may stem from a biological or organic condition, a psychological condition and/or a social condition [3]. At the level of the individual, doctors aim to determine the etiology of the dysfunction and treat it accordingly. At the level of the population, however, researchers aim to predict which factors might put one population at risk over another population. Identifying these predictors and their effect (whether protective or risk-inducing) may aid health professionals to better detect and potentially prevent sexual problems from arising.

Past literature reviews have identified a number of similar biological, psychological and social predictors of female sexual dysfunction across different populations. In a 1990 systematic review on sexual dysfunction in both men and women, age, education, socio-economic status, and marital status were found to have an influence on male and female sexual dysfunction [4]. West et al.'s 2004 systematic review on female sexual dysfunction uncovered further predictors such as physical health (both observed and perceived), psychological health, race/ethnicity, number of premarital partners, religion, sexual orientation, communication with partner and attitude towards sexuality [5].

Predictors of sexual dysfunction are numerous, and various approaches can be used to classify and assess them. The gold standard in epidemiological research is to identify the exact effect sizes of predictors, that is, the quantitative effect of a specific risk factor or protective factor in a population expressed as a measure of relative and/or attributable risk. Such quantitative analyses require a certain degree of homogeneity in the observed population as well as in the measurement of the construct of interest, and therefore often focus on a limited number of predictors. In this analysis, however, the aim was not to quantify the magnitude of the effect of a single predictor but to uncover the breadth of predictors in heterogeneous populations around the globe and to identify possible trends. In order to provide a more structured analysis of the multifaceted risk factors and protective factors in these populations, the predictors of female sexual dysfunction were examined using paradigms which focused on gender inequality.

Two global studies, in particular, have shed some light on the association between female sexual function and gender inequality. In 2004, researchers from the Global Study of Sexual Attitudes and Behaviors (GSSAB) began publishing their results on a survey of 27,500 men and women in 29 countries [6]. In the wealth of data, they identified common gender-based trends of sexual attitudes in behaviors across the 29 surveyed countries [7]. The participants' subjective responses on four components of sexual health (satisfaction with sexual functioning, physical pleasure, emotional pleasure, and importance of sex) revealed three clusters or so-called "sexual regimes." A gender-equal sexual regime was found in typically Western countries. One type of male-centered sexual regime was identified in a mixed group of countries, and a second type of male-centered sexual regime was seen in predominantly Asian countries. Satisfaction with sexual functioning was one of four components composing the sexual well being score. A closer look at the responses in each country revealed that women in gender-equal regimes rated their satisfaction with sexual functioning at 64.4-91.1\% [median 78.1\%], while women in the mixed male-centered and the Asian male-centered regimes rated their satisfaction with sexual functioning at 44.5-82.1\% [median 56.7\%] and 39.7-61.3\% [median 45.5\%], respectively. Similar trends in women's responses were also seen in the other three components of the sexual well being score. In all three clusters/regimes, women had consistently lower scores than men in terms of their sexual well being. However, differences were greater between men and women in the two male-centered regimes.

A 2016 systematic review and meta-analysis assessed the prevalence rate of female sexual dysfunction in 215,740 reproductive-age women worldwide and found the $41 \%$ of these women report some form of female sexual dysfunction [1]. A meta-regression of the collected data showed a positive correlation between the prevalence of female sexual dysfunction and the level of gender inequality in a country (Gender Inequality Index from the United Nations Development Program) [1, 8]. Further stratification of these results by world region illustrated that more developed regions (e.g. Europe and North America) typically had rates of female sexual dysfunction below 40\%, whereas developing regions such as the Middle East and Africa had rates as high as 62\%. The meta-analysis also stratified the prevalence rates according to sexual regimes, as identified by the GSSAB research group. While the overall prevalence rate of female sexual dysfunction was not significantly different between the three regimes, there were in fact significantly lower rates of pain disorders, orgasm disorder and lubrication difficulties in the gender-equal regime compared to the mixed and Asian male-centered sexual regimes. The results of these two large-scale studies cannot show causality between sexual dysfunction and gender inequality, but they do underline the importance of 
examining sexual health outcomes in terms of the level of gender inequality in a society.

With the rise in publications on female sexual dysfunction [9], an updated summary of the predictors of female sexual dysfunction is needed. The following qualitative analysis and its narrative synthesis will summarize the risk and protective factors related to female sexual dysfunction among reproductive-age women in multiple countries and simultaneously shed further light on the aspect of gender inequality.

\section{Methods}

\section{Protocol and registration}

The methods for this systematic literature search have been developed according to the recommendations from the Preferred Reporting Items for Systematic Reviews and Meta-Analyses (PRISMA) statements [10]. This protocol has been registered with the International Prospective Register of Systematic Reviews (PROSPERO): CRD42014009526 and is available in published form [11].

\section{Search strategy and selection criteria}

Data for this review were identified by searches of Medline, Embase, PsycINFO, Web of Science and other relevant databases, using the terms "sexual dysfunction", "female", and "epidemiology". Searches were limited to studies of humans, to the English language, and to the time frame January 1, 2000 until July 10, 2014.

The search was performed by an experienced medical research librarian. All titles and abstracts were screened for their relevance. If there was any uncertainty about an abstract's relevance at this stage, the article remained included until the full text was reviewed. Articles identified through hand searches were considered for inclusion based on their titles.

A standard form was designed and used to evaluate the full-text publications for inclusion. Two investigators independently assessed each publication for eligibility and compared their results. If there was a discrepancy in their assessment, a final decision was taken based on discussions with a third reviewer. For multiple publications based on a single study, the most current and/or inclusive study was selected. A second hand search was performed using the reference lists of all included articles.

Cross-sectional, cohort, and case-control studies were eligible for this systematic review. Validation studies, reviews, reports, and commentaries were not included. Clinical populations or populations of women who were surveyed for a particular disease or illness were excluded, as the purpose of this systematic review was to capture the prevalence and risk factors present in the general population. Studies that addressed FSD in infertile women or couples and studies that examined spouses and partners of men with erectile disorder were also excluded.

The research question focused on reproductive-age women in the general population. Any studies that focused primarily on menopausal, postmenopausal, pregnant, or lactating women were excluded. Because several epidemiologic studies covered a broad age range of women, a numeric cutoff was used for the studies that did not specify which women were of reproductive age. Studies were included if (i) all women surveyed were described as premenopausal, (ii) the age range of the participants was between menarche and 49 years, or (iii) data on women no older than 49 years could be extracted from the entire population.

Further details regarding the search strategy, search terms, the assessment of bias, and the meta-analytical prevalence of female sexual dysfunction have been published elsewhere or may be requested from the corresponding author [1]. The PRISMA flow chart of the 135 studies included in this systematic review can be seen in Fig. 1.

\section{Data collection}

Data were extracted from the included studies using an electronic data extraction form created in Microsoft Access. The extraction form was pre-designed and pilot-tested. A pilot test was performed with 20 randomly selected publications on the prevalence of female sexual dysfunction. Based on the results of the pilot test, the form was revised by the investigators.

Analyses of odds ratios and correlations within the included studies were examined in order to determine which predictors proved to be significant. Significant predictors $(P<0.05)$ were listed according to the following domains: overall female sexual dysfunction, hypoactive sexual desire disorder, female sexual arousal disorder, lubrication difficulties, female orgasmic disorder, and pain disorders. Where possible, information on significant predictors was taken from multivariate analyses; otherwise data from univariate analyses were extracted.

Once all data were extracted from the included publications, the data were examined and verified by a second author. Discrepancies in data entry were documented, discussed and revised accordingly.

\section{Qualitative analysis}

A summary table describing each publication and its respective, significant risk/protective factors was created. Non-significant risk factors were also listed. The predictors extracted from the publications were then stratified using two different schemes: 1 ) the type of sexual regime and 2) the level of gender inequality/human development. For both schemes, similar risk factors/protective factors were grouped together, e.g. the term "relationship 


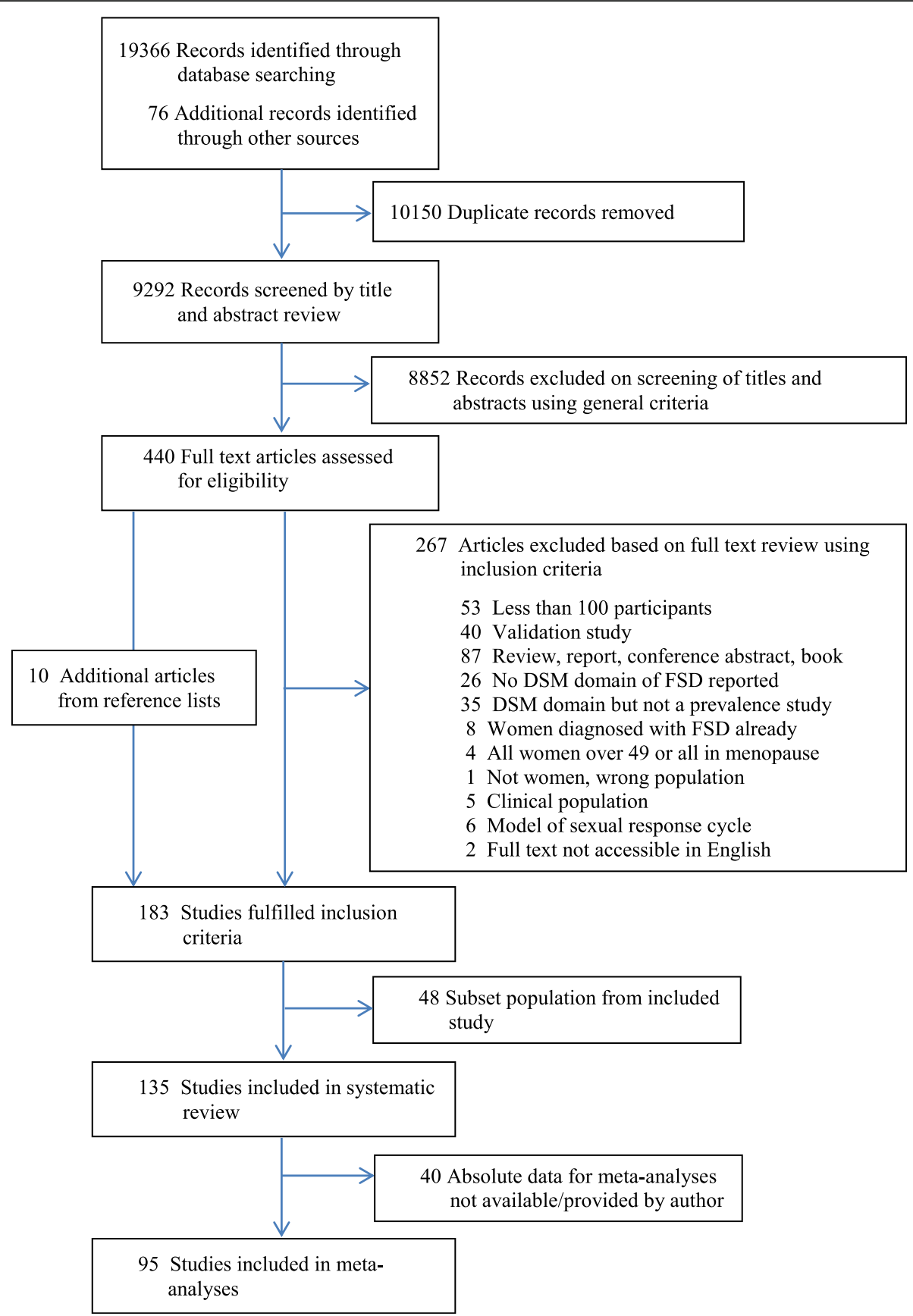

Fig. 1 PRISMA flow chart showing number of citations retrieved from a systematic literature search in multiple databases

dissatisfaction" was used to represent terms such as "dissatisfied in marriage" and "poor relationship with husband;" the term "partner" was used instead of "husband" or "spouse."

The type of sexual regime was based on results from the Global Study of Sexual Attitudes and Behaviors (GSSAB) which surveyed 27,500 men and women in 29 countries [7]. Using clustered data on sexual attitudes, satisfaction, behaviors, as well as prevalence rates of sexual dysfunction,
Laumann et al. identified three types of sexual regimes worldwide: a gender-equal regime, a mixed male-centered regime, and an Asian sexual regime. The gender-equal sexual regime consisted primarily of Western/European nations (Austria, Belgium, France, Germany, Spain, Sweden, the United Kingdom, Mexico, Australia, Canada, New Zealand, South Africa, and the United States). The mixed male-centered sexual regime included Mediterranean countries (Algeria, Egypt, Israel, Italy, Morocco, and 
Turkey) as well as Korea, Malaysia, the Philippines, and Singapore. The third cluster, also considered male-centered, entailed only Asian countries: China, Indonesia, Japan, Taiwan, and Thailand (see Table 1).

The significant predictors of female sexual dysfunction were stratified according to type of sexual regime and presented in a Venn diagram or in narrative form. For the individual domains of female sexual dysfunction (desire disorder, arousal disorder, lubrication difficulties, orgasm disorder and pain disorder), a narrative synthesis of the results was given.

For the level of human development, the Gender Inequality Index (GII), created by the United Nations Development Program, was used. The GII is based on current (ranging from 2010 to 2015) rates of maternal mortality, adolescent birth, women's secondary education, women's political involvement, and labor force participation [8]. Using these data, each country is given a GII value between 0 and 1: the higher the value, the greater the inequality between men and women. Based on the GII value, countries are sorted into quartiles with the following human development groups: very high human development, high human development, medium human development, and low human development. A link to the GII and the human development groups can be found here: http://hdr.undp.org/en/composite/GII .

The significant risk factors of female sexual dysfunction were stratified according to level of human development and illustrated in the form of word clouds. Due to a large number of highly-specific medical conditions addressed in these 135 publications, only the significant risk factors which were identified in at least two separate studies were included in the word cloud. This allowed for better comparison across the levels of human development. Furthermore, the word clouds were designed to be sensitive to the number of publications in which a certain risk factor had been identified, i.e. a risk factor which was identified in four publications would be presented in a larger font in the word cloud than a risk factor identified in only two publications. For the individual domains of female sexual dysfunction (desire disorder, arousal disorder, lubrication difficulties, orgasm disorder and pain disorder), a narrative synthesis of the results was provided.

\section{Results}

Eligible studies from the systematic literature search

The systematic literature search resulted in 135 eligible studies from 41 countries. Of the 135 studies, 97 publications (72\%) from 34 countries analyzed predictors of female sexual dysfunction in populations of reproductive-age women [12-109]. A complete listing of both significant and non-significant predictors for each publication can be found in the supplementary material online [see Additional file 1]. Ninety-four publications from 33 countries reported significant predictors and were the basis for the following qualitative analyses (see Table 2).

\section{Significant predictors of female sexual dysfunction}

A summary of the significant predictors of female sexual dysfunction and each of its domains can be found in Table 3 Significant risk factors which were consistent in all domains of female sexual dysfunction were: poor physical health, poor mental health, poor partner health, partner unemployment, low education of partner, stress, abortion, menopause, genitourinary problems, female genital mutilation, relationship dissatisfaction, sexual dysfunction of partner, sexual abuse, and being religious. Factors which consistently had a significant, protective effect across all domains were: older age at marriage, exercising, daily affection, intimate communication, having a positive body image, sex education and finding sex to be "important." For some factors, mixed results were reported in the studies, and a clear tendency (whether risk-inducing or protective) could not be found: age, education, employment, parity, being in a relationship, frequency of sexual intercourse, race, alcohol consumption, smoking and masturbation.

\section{Significant predictors of female sexual dysfunction: Type of sexual regime}

Using the classification system from the GSSAB, the significant predictors extracted from the 94 publications were then analyzed based on the type of sexual regime in the given country (see Table 1 in Methods). The GSSAB data covered 29 countries, 15 of which were represented among the 94 publications. Thirty-eight publications could not be categorized, because the country of study had not been investigated in the GSSAB. However, 56 publications could be categorized into the following types

Table 1 GSSAB sexual regimes according to Laumann et al. [7]

\begin{tabular}{|c|c|c|}
\hline \multirow{2}{*}{$\begin{array}{l}\text { Countries with a gender-equal sexual } \\
\text { regime }\end{array}$} & \multicolumn{2}{|l|}{ Countries with a male-centered sexual regime } \\
\hline & mixed & Asian \\
\hline $\begin{array}{l}\text { Austria, Belgium, France, Germany, Spain, } \\
\text { Sweden, the United Kingdom, Mexico, } \\
\text { Australia, Canada, New Zealand, South } \\
\text { Africa, and the United States }\end{array}$ & $\begin{array}{l}\text { Algeria, Egypt, Israel, Italy, Morocco, Turkey, } \\
\text { Korea, Malaysia, the Philippines, and Singapore }\end{array}$ & China, Indonesia, Japan, Taiwan, and Thailand \\
\hline
\end{tabular}


Table 2 Characteristics of studies

\begin{tabular}{ll}
\hline Categorical variable & $\mathrm{N}(\%)$ \\
\hline World region & 94 \\
Europe & $31(33.0)$ \\
Non-Europe West $^{\mathrm{a}}$ & $14(14.9)$ \\
Asia & $19(20.2)$ \\
Central and South America & $10(10.6)$ \\
Africa & $9(9.6)$ \\
Middle East & $11(11.7)$ \\
Sexual regime & 56 \\
gender-equal & $27(48.2)$ \\
male-centered & $19(33.9)$ \\
Asian (male-centered) & $10(17.9)$ \\
Human development group & 92 \\
very high & $43(46.7)$ \\
high & $35(38.0)$ \\
medium & $11(12.0)$ \\
low & $3(3.3)$ \\
\hline a USA, Canada, South Africa, New Zealand, Australia
\end{tabular}

of sexual regimes: gender-equal regimes $(n=27)$, male-centered regimes $(n=19)$, and Asian, male-centered sexual regimes $(n=10)$. Figure 2 illustrates the significant risk factors for female sexual dysfunction, shared among women living in various sexual regimes.

Independent of the type of sexual regime, a lack of sexual knowledge, medical illness, poor physical health, older age, depression and smoking were found to be common significant risk factors for female sexual dysfunction. Some risk factors were however unique to the individual regimes. The studies performed in countries with gender-equal sexual regimes $(n=27)$ reported risk factors which are associated a) with illnesses in Western lifestyle: cardiovascular disease, taking anti-depressants, sleeping problems, and polypharmacy or b) with sexual intimacy: difficulty talking with partner about sex, more than 10 sexual partners, relationship dissatisfaction, bisexual preference, and sexual abuse/rape. Studies performed in the mixed male-centered sexual regime $(n=$ 19) indicated risk factors primarily associated with early partnership and reproduction: young age at marriage, older partner, arranged marriage, high number of births and nulliparity. Other risk factors unique to this regime were female genital mutilation, restrictive upbringing, rural living and dieting. Although there were not very many studies in Asian sexual regimes $(n=10)$, there was a trend in partner-related factors: sharing bedroom with non-spouse family member, living separate from partner, and poor partner health. Two significant risk factors which surfaced in Asian studies were also mid to upper income as well as alcohol consumption. Some of the significant protective factors noted in the various regimes included: higher frequency of intercourse (gender-equal and male-centered), use of contraceptives as well as sex education (male-centered), and frequent communication with partner (Asian).

\section{Significant predictors in the domains of female sexual dysfunction: Type of sexual regime}

Risk factors for desire disorder were multitudinous but rather similar across all regimes (socio-economic difficulties, relationship difficulties, physical and mental health issues, etc.). The protective factors for desire disorders in the regimes were however unique. In gender-equal regimes, smoking and alcohol consumption had a protective effect, as well as spontaneous sexual initiation, masturbation, being in a non-exclusive relationship and having an imbalance of commitment in a relationship (woman more committed than man). For the mixed male-centered regime, alcohol consumption had a protective effect, as well as spontaneous sexual initiation, a varied sexual repertoire and sex education. Finally, for Asian male-centered sexual regimes, having a liberal attitude towards sex and being pregnant were protective factors for desire disorder.

Protective factors for arousal disorder in gender-equal regimes were: higher education, emotional intelligence, never married /widowed / divorced/separated, middle age (30-49), and using hormone replacement therapy. In contrast, being single was a risk factor for arousal disorder in the mixed male-centered regime and higher education was found to be a risk factor in Asian countries. Notably, having liberal sex values and a high acceptance for pornography were two further risk factors for arousal disorder in the Asian male-centered sexual regime.

Older age was a risk factor in mixed male-centered sexual regimes and gender-equal sexual regimes; relationship dissatisfaction was unique to the gender-equal sexual regime while being single was unique to the male-centered sexual regime. No protective factors for lubrication difficulties could be identified in the studies.

Protective factors of orgasm disorder across all regimes are worth highlighting: age group 30-40 (gender-equal), finding sex important (gender-equal and Asian male-centered), using contraceptives and being unmarried (mixed male-centered). With orgasmic disorder, there were more risk factors associated with the partner in both gender-equal and Asian regimes: relationship dissatisfaction, being unsatisfied with size/thickness of partner's penis, low foreplay enjoyment, unidirectional coital initiation, no daily affection, unattractive partner, adulterous partner, and partner has sexual dysfunction. Other risk factors which were unique to the Asian 
Table 3 Summary of predictors for female sexual dysfunction and its domains

\begin{tabular}{|c|c|c|c|}
\hline & Risk factor & Unclear effect & Protective factor \\
\hline $\begin{array}{l}\text { Female } \\
\text { Sexual } \\
\text { Dysfunction }\end{array}$ & $\begin{array}{l}\text { Demographic: unemployment, } \\
\text { unemployment of partner, low education of } \\
\text { partner, low SES, illiteracy, economic } \\
\text { hardship, restrictive upbringing, sharing a } \\
\text { bedroom with family members. Health and } \\
\text { wellbeing: poor physical health, poor } \\
\text { perceived health, poor mental health, low } \\
\text { life satisfaction, poor quality of life, poor } \\
\text { social relationships, environment with } \\
\text { limited opportunities, chronic illness, heart } \\
\text { disease, obesity, physical disability in } \\
\text { previous year, depression, anxiety, taking } \\
\text { antidepressants, dieting, alcohol, smoking, } \\
\text { sleeping problems, polypharmacy. OBGYN: } \\
\text { high number of births, ever pregnant, use of } \\
\text { IUD, cervical erosion, late debut menarche, } \\
\text { abnormal menstrual pattern, female genital } \\
\text { mutilation, guilt about abortions, difficult } \\
\text { delivery, menopause, urinary incontinence, } \\
\text { endometriosis, yeast infection, gynecological } \\
\text { surgery, genitourinary problems, pelvic } \\
\text { inflammatory disease, hysterectomy, STI. } \\
\text { Partner: poor partner health, partner smokes, } \\
\text { older partner, partner has SD, relationship } \\
\text { dissatisfaction, arranged marriage, } \\
\text { polygamous relationship, living separately } \\
\text { from partner, long duration of relationship. } \\
\text { Sexual life: dissatisfaction with sex life, no / } \\
\text { too little foreplay, no genital contact } \\
\text { without intercourse (past month), } \geq 10 \\
\text { lifetime sexual partners, negative attitude } \\
\text { toward sex, difficulty talking to partner } \\
\text { about sex, not competent at first } \\
\text { intercourse, bisexual preferences, } \\
\text { homosexual preferences, non-sensuality, } \\
\text { sexual abuse, sexual harassment, rape, } \\
\text { dissatisfaction with partner's penis size }\end{array}$ & $\begin{array}{l}\text { age, level of education (high/low), level of } \\
\text { income (high/low), residence (rural/urban), } \\
\text { masturbation, use of contraceptives, use of } \\
\text { HRT, being in a relationship/marriage, parity } \\
\text { (having children/not having children), race }\end{array}$ & $\begin{array}{l}\text { older age at marriage, faithful partner, } \\
\text { access to private health care, emotional } \\
\text { intelligence, frequent communication with } \\
\text { partner, intimate communication, only } 1 \\
\text { current sexual partner, pregnancy in last } \\
\text { year, steady relationship without } \\
\text { cohabitation, higher frequency of } \\
\text { intercourse, church attendance, sex } \\
\text { education, "sex is important" }\end{array}$ \\
\hline $\begin{array}{l}\text { Desire } \\
\text { Disorder }\end{array}$ & $\begin{array}{l}\text { Demographic: unemployment of partner, } \\
\text { low education of partner, low SES, being } \\
\text { religious, urban living, having young } \\
\text { children, sharing a bedroom with family. } \\
\text { Health and wellbeing: poor physical health, } \\
\text { poor mental health, low life satisfaction, } \\
\text { chronic illness, breast cancer, heart disease, } \\
\text { diabetes, thyroid problems, hypertension, } \\
\text { depression, anxiety, post-traumatic stress dis } \\
\text { order (PTSD), drug addiction, habitualized } \\
\text { negative thinking about oneself, }\end{array}$ & $\begin{array}{l}\text { age, level of education (high/low), level of } \\
\text { income (high/low), employment } \\
\text { (unemployed/full-time), masturbation, being } \\
\text { in a relationship/marriage, race, frequency of } \\
\text { intercourse }\end{array}$ & $\begin{array}{l}\text { older age at marriage, moderate alcohol } \\
\text { consumption, smoking, spontaneous sexual } \\
\text { initiation, varied sexual repertoire, exercising, } \\
\text { non-exclusive relationship, liberal attitudes } \\
\text { towards sex, good communication with } \\
\text { partner, intimate communication, early } \\
\text { sexual debut, having }>1 \text { lifetime sexual } \\
\text { partner, daily affection, currently pregnant, } \\
\text { imbalance of commitment (woman more } \\
\text { committed than man), sex education, "sex } \\
\text { is important" }\end{array}$ \\
\hline
\end{tabular}
abtion about how housework is done. OBGYN: late debut menarche, abnormal menstrual pattern, STI, female genital mutilation, tubal ligation, cervical erosion, ever pregnant, fear of pregnancy, birth in past year, menopause, urinary incontinence, genitourinary problems, hysterectomy, hormonal contraceptives, low hormones, multiparity. Partner: partner has $\mathrm{SD}$, relationship dissatisfaction, internal stress with partner, habitualized negative thinking about partner, being widowed, long dur ation of relationship, married more than once. Sexual life: non-sensuality, sexual abuse, childhood sexual abuse, no / too little foreplay, low foreplay enjoyment, low sexual satisfaction, unidirectional coital initiation 
Table 3 Summary of predictors for female sexual dysfunction and its domains (Continued)

\begin{tabular}{llll}
\hline & Risk factor & Unclear effect & Protective factor \\
\hline $\begin{array}{l}\text { Arousal } \\
\text { Disorder }\end{array}$ & $\begin{array}{l}\text { Demographic: unemployment of partner, } \\
\text { low education of partner, low SES, being } \\
\text { religious. Health and wellbeing: poor } \\
\text { physical health, poor mental health, chronic } \\
\text { illness, arthritis, thyroid problems, irritable } \\
\text { bowel, anxiety, depression, polypharmacy, }\end{array}$ & $\begin{array}{l}\text { age, level of education (high/low), } \\
\text { employment (unemployed/full-time), being }\end{array}$ & $\begin{array}{l}\text { older age at marriage, divorced/widowed/ } \\
\text { separated, emotional intelligence, exercising, } \\
\text { intimate communication, positive body }\end{array}$ \\
& & $\begin{array}{l}\text { image, higher frequency of intercourse, use } \\
\text { of HRT, daily affection, "sex is important" }\end{array}$
\end{tabular}

level of income (high/low), level of

education (low/high), being in a

relationship/marriage older age at marriage, faithful partner, intimate communication, sex education, "sex is important"
Orgasm

Disorder partner, low SES, economic hardship, sharing a bedroom with family, manual laborer. Health and wellbeing: poor physical health, poor perceived health, poor mental health, chronic illness, anxiety, seeking medical help, physical abuse. OBGYN: abnormal menstrual pattern, late debut menarche, cervical erosion, infertility, urinary incontinence, STI, menopause. Partner: partner has SD, relationship dissatisfaction, long duration of relationship, partner is unattractive. Sexual life: masturbation, higher frequency of intercourse, "sex is dirty", knowledge of clitoris

Demographic: unemployment, unemployment of partner, low education of partner, urban living, sharing a bedroom with family, being religious, job insecurity, Iow SES, manual laborer. Health and wellbeing: poor physical health, poor mental health, chronic illness, smoking, alcohol, stress/anxiety, feelings of guilt, arthritis, thyroid problems, depression, critical life event, seeking medical help. OBGYN: late debut menarche, abnormal menstrual pattern, cervical erosion, STI, urinary incontinence, multiparity, abortion, fear of pregnancy, menopause. Partner: partner has $S D$, relationship dissatisfaction, partner is unattractive, polygamous relationship, married more than once, long duration of marriage. Sexual life: low foreplay enjoyment, masturbation, knowledge of clitoris, non-sensuality, "sex is a duty", antimasculinity, sexual embarrassment, rape by partner, no /too little foreplay, never/unsure if ever had orgasm, unidirectional coital initiation, sexual dissatisfaction, absence of sexual pleasure, unsatisfied with thickness/ size of partner's penis

Pain Demographic: unemployment, working

Disorder overtime, unemployment of partner, low education of partner, urban living, sharing a bedroom with family, being religious, low SES. Health and wellbeing: poor physical health, poor perceived health, poor mental health, chronic illness, lung disease, arthritis, lower back pain, anxiety, exhaustion, seeking age, level of education (low/high), level of income (high/low), being in a relationship/ marriage, race, frequency of intercourse

age, level of education (high/low), level of income (high/low), being in a relationship/ marriage, mode of delivery, parity (having children/not having children), race, frequency of intercourse older age at marriage, faithful partner, exercising, good communication with partner, intimate communication, satisfactory relationship with partner, use of contraceptives, daily affection, being divorced, married less than 5 years, sex education, "sex is important" older age at marriage, at least 4 years of regular intercourse, positive body image, liberal attitudes towards sex, currently pregnant, sex education, "sex is important" 
Table 3 Summary of predictors for female sexual dysfunction and its domains (Continued)

\begin{tabular}{|c|c|c|}
\hline Risk factor & Unclear effect & Protective factor \\
\hline $\begin{array}{l}\text { medical help, colitis, heavy lifting, } \\
\text { constipation. OBGYN: late debut menarche, } \\
\text { abnormal menstrual pattern, menopause, } \\
\text { abortion, infertility, ever pregnant, early } \\
\text { (<15 years old) sexual debut, use of IUD, } \\
\text { hormonal contraceptives, STI, chronic urinary } \\
\text { tract infections, urinary incontinence, } \\
\text { genitourinary problems, cervical erosion, } \\
\text { pelvic organ prolapse, pelvic inflammation. } \\
\text { Partner: partner smokes, relationship } \\
\text { dissatisfaction, planning more children. } \\
\text { Sexual life: masturbation, "sex is dirty", varied } \\
\text { sexual practices, sexual dissatisfaction, } \\
\text { non-sensuality }\end{array}$ & & \\
\hline
\end{tabular}

SD sexual dysfunction, SES socio-economic status, IUD intrauterine device, HRT hormone replacement therapy, STI sexually transmitted infection

male-centered sexual regime were masturbation in the past 12 months and knowledge of the clitoris.

Lastly, for pain disorder, older age was found to be a risk factor and a protective factor for all three sexual regimes. A complete list of risk factors and protective factors for all domains according to sexual regime can be found in the supplementary material online [see Additional file 2].

\section{Significant predictors of female sexual dysfunction: Level of human development}

Using the GII quartiles, the predictors were assessed in terms of the level of human development (HD) in the given country. The GII data cover all countries which were represented in our data. Two multinational studies among the 94 publications surveyed women in countries with different GII quartiles, thus they could not be included in the current analysis [27, 86]. However, 92 studies could be sorted into the following quartiles: very high human development $(n=43)$, high human development $(n=35)$, medium human development $(n=11)$, and low human development $(n=3)$. Figure 3 uses word clouds to illustrate the frequency and variety of significant risk factors for female sexual dysfunction, stratified by the level of human development.

The risk factors illustrated in the word clouds have commonalities and differences. In very high, high and medium HD groups, menopause and older age were risk

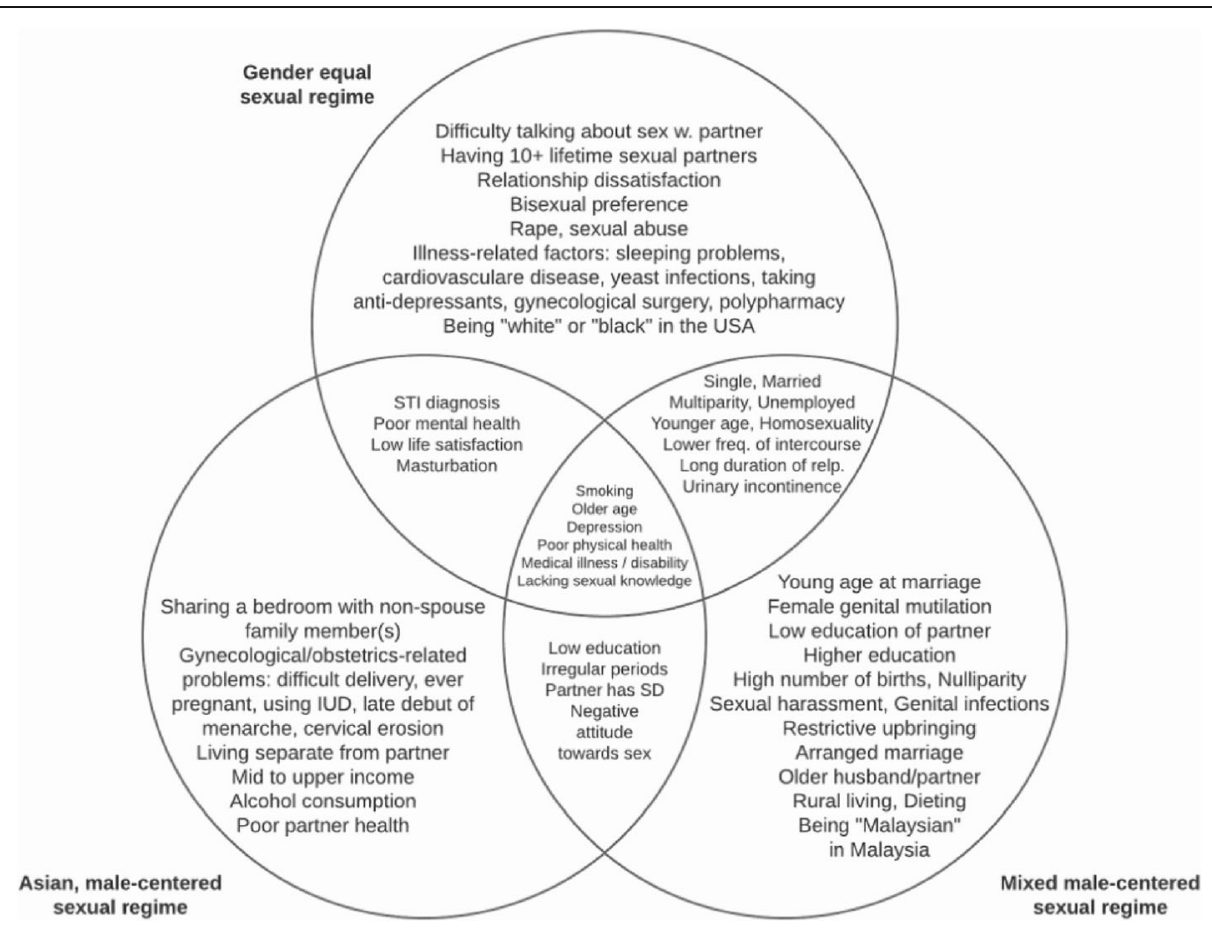

Fig. 2 Venn diagram illustrating shared and unique risk factors for each sexual regime $(n=56)$ 


\begin{tabular}{|c|c|c|c|}
\hline Very high human development & High human development & Medium human development & Low human development \\
\hline 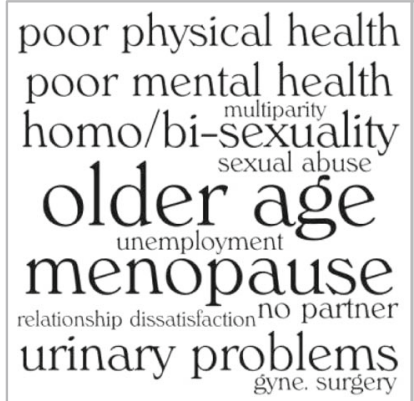 & 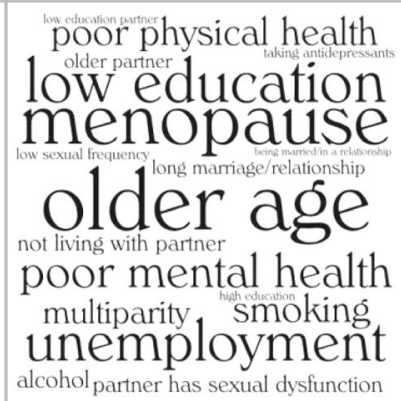 & $\begin{array}{l}\text { female genital mutilation } \\
\text { menow education } \\
\text { partner has sexual dysfunction } \\
\text { older age } \\
\text { multiparity } \\
\text { long marriage/relationship }\end{array}$ & $\begin{array}{l}\text { guilty feelinǵs about previous abortions } \\
\text { sexual abuse } \\
\text { polygamous relationship } \\
\text { high education } \\
\text { on medication } \\
\text { poor physical health }\end{array}$ \\
\hline
\end{tabular}

factors in the observed studies. Although this analysis focused on reproductive-age women, some studies with broad age ranges also included women going through menopause. These risk factors were not apparent in studies in countries from the low HD group (Nigeria, Kenya, Uganda and Ethiopia). Contradictory risk factors were evident, e.g. low vs. high education. Risk factors related to sexual oppression were exposed through the stratification process. Homosexual and bisexual women are at a greater risk for sexual dysfunction in the very high HD group, while women who are in polygamous relationships and those who have gone through female genital mutilation are at risk in medium and low HD groups. Sexual abuse was a risk factor in both very high and low HD groups.

Protective factors in studies conducted in countries with very high HD were: good overall health, higher education, positive body image, exercising, masturbating, moderate alcohol consumption, smoking, higher number of lifetime partners, church attendance, intimate communication, and the use of hormone replacement therapy. Studies conducted in countries with high HD revealed similar protective factors: good overall health, higher education, moderate alcohol consumption, and good communication with partner. Other significant protective factors in the high HD group were: using contraceptives, having sex education, finding sex to be "important," an older age at marriage, spontaneous rather than unidirectional sexual initiation, and a varied sexual repertoire. Studies in the medium and low HD groups yielded only a few significant, protective factors; these were higher income, having some education, and the use of hormone replacement therapy.

\section{Significant predictors in the domains of female sexual dysfunction: Level of human development}

Risk factors and protective factors in each domain of female sexual dysfunction were analyzed, but the findings did not provide further insight beyond that which had already been exposed through the previous analyses. A list of the significant risk factors for all domains according to level of human development can be found in the supplementary material online [see Additional file 3].

\section{Discussion \\ Indication of imbalance}

Through the increase in population-based studies around the globe, the number and variety of predictors have increased as well. This is the first systematic review to address significant predictors of female sexual dysfunction for each domain of sexual dysfunction. Due to the heterogeneous populations and the fact that studies assessed different domains of female sexual dysfunction, a wide variety of predictors could be identified among the 94 international studies. Factors which consistently had a significant, protective effect across all domains were: older age at marriage, exercising, good overall health, daily intimacy and relationship satisfaction, having a positive body image, sex education and finding sex to be "important." Risk factors were frequently related to both physical and mental health of women. Other significant factors such as age, partnership, and parity showed mixed protective and risk effects in the populations and within the domains of sexual dysfunction.

Further stratification of these predictors was essential to this analysis. Because there were lower meta-analytical prevalence rates in gender equal sexual regimes and because of the correlation between high female sexual dysfunction rates and high gender inequality [1], the risk factors and protective factors were examined through paradigms of gender inequality in order to better understand trends in predictors of female sexual dysfunction.

\section{Stratification reveals research gap}

Trends of predictors could be identified once the studies were stratified according to type of sexual regime (56 studies). In gender-equal sexual regimes (Western/European countries), risk factors tended to be related to 
chronic illness and mental health, as well as to quality of life factors. In the Asian male-centered sexual regime, risk factors were related to gynecological health but also to family and partner - more so than in the other two regimes. In the mixed male-centered sexual regimes (primarily Arab and African countries), risk factors including female genital mutilation, restrictive upbringing and high number of births point towards underlying challenges in women's rights and women's reproductive health.

Risk factors such as older age, poor health, and relationship dissatisfaction were found in all human development groups, regardless of the level of gender inequality $(n=92)$. This stratification also revealed that far fewer studies can be found in countries with high to very high gender human development vs. those with medium to low human development (78 vs. 14). Studies from countries with low/medium human development accounted for less than $15 \%$ of all studies in this analysis, indicating a lack of research in these countries and limited knowledge concerning the predictors of female sexual dysfunction in these populations.

\section{Risk factor or protective factor?}

Former systematic reviews on sexual dysfunction primarily included studies from Western nations, i.e. the predictors of sexual dysfunction were based on gender-equal sexual regimes/countries with high development. With the growing number of studies in developing nations and Asian countries, it is evident that not all risk factors and protective factors are universal. In a large US study, education was identified as a protective factor against sexually distressing problems [87]. In studies from Iran and Jordan, young women who are educated and have gainful employment are less likely to show symptoms of sexual dysfunction [12, 84, 99]. However, several studies from China have shown that young women who have higher education were more likely to report sexual dysfunction $[62,109,110]$. Through higher education, these women gain increased awareness of their sexual needs and rights, and such women tend to feel more disappointed with their marital and sexual relationships, which may lead to poor sexual functioning $[89,111]$. Similarly, while increased frequency of sexual intercourse was found to have a protective effect in most cultures, some studies in traditional cultures showed that frequent sex might be demanded by the partner and is therefore a risk factor for sexual dysfunction in these women [62, 73].

Some predictors showed variation within the domains. For example, female sexual dysfunction has generally been shown to be age-related [112]. Older age tends to be a risk factor for all domains except for pain disor$\operatorname{der}(\mathrm{s})$, where it is shown to have a protective effect.
Other studies showed a U-shaped prevalence of sexual dysfunction, with younger and older women being most affected [113]. Women in their 30s may show fewer symptoms of dysfunction as they learn more about their preferences and become more comfortable accepting and expressing their sexuality [103]. Similar variation in the effect (whether positive or negative) was found for employment, income, partnership status, and parity.

Laumann et al. established two different male-centered sexual regimes, because the Asian sexual regime had clear differences in attitudes and behaviors when compared to Middle Eastern or African countries [7]. Risk factors such as high acceptance of pornography, masturbation, liberal sex values and knowledge of the clitoris were unique to Asian population studies. The authors explain that in these societies such women are considered non-traditional. Women who do not conform to traditional female roles in these societies may experience greater difficulties with their male partners [62].

Two further predictors which were shown to have a mixed effect on women's sexual functioning were alcohol consumption and smoking. In the majority of studies, these factors did not have an effect on sexual functioning. However, selected studies suggest that these factors may be a mediating factor for improved sexual desire. In a Puerto Rican study, smoking was shown to have a significant protective effect in respect to desire disorder [21]. The authors describe that it may not be the act of smoking itself that is protective but rather the liberal lifestyle associated with women who smoke in that society. Similarly with alcohol consumption, the studies generally showed a non-significant effect, but three studies revealed a protective effect of moderate alcohol consumption [13, 21, 41]. In the three countries represented in the studies (Brazil, Denmark, Puerto Rico), the authors came to the conclusion that moderate alcohol consumption is associated with lower rates of desire disorder. As with smoking, the underlying component may not be the alcohol, but instead a less restrictive approach to "traditional" female roles.

\section{Challenges in preventing sexual dysfunction}

Protective factors, regardless of population, regime, or level of development, were: sex education, exercise, older age at marriage, daily affection, intimate communication, having a positive body image, and finding sex to be "important." Since several of these factors are modifiable, preventive measures could be taken to potentially avert the onset of female sexual dysfunction. However, these factors may be more complicated to address in some countries than in other countries, as they are closely entwined with culture.

Sex education has a significant protective effect [13, $61,69]$, but sex education and reproductive health 
services in many countries tend to focus exclusively on married women, as it is culturally unacceptable for single women to have sexual relations. The needs of young, unmarried, sexually-active women may therefore go unaddressed [114].

Similarly, while exercise may seem like a reasonably modifiable risk factor for female sexual dysfunction, mobility, e.g. exercising, traveling and moving about in public spaces, can be challenging for women living in countries with high gender inequality. An international study of 70 countries revealed that women's lack of autonomy and resources to move freely can result in mobility disability [115]. This means that women in countries with higher gender inequality may not be able to have healthy lifestyles, e.g. getting enough physical activity or traveling to the doctor to receive care.

Furthermore, male-dominated cultures, in which sexual behavior is oriented more towards reproduction, tend to suppress women's sexual needs and pleasure and to discount the relational meaning of sex [7, 62]. Current practices in these cultures such as arranged marriages, marriages at a young age, polygamy and female genital mutilation are associated with significantly higher levels of sexual dysfunction in women [19, 38, 42, 44, 73].

Finally, women in conservative cultures women may also be too timid to express their needs or feel that it is socially unacceptable to discuss sexual problems with their partner $[65,76,111]$. While lower rates of sexual dysfunction are found in women who share intimate communication with their partner [67], this may be easier in some cultures than in others.

Challenges in improving women's health are numerous. Gender inequality creates an additional barrier in terms of women's sexual and reproductive health. It is for this reason that the World Health Organization has made it one of its Millennium Development Goals to promote gender equality and empower women [114]. Research on gender inequality takes a considerable amount of time, as changes in cultural patterns do not take place overnight. However, health studies have confirmed the association between gender inequality and women's wellbeing. A recent ecological study from Stanford University on global HIV prevalence rates and the GII showed an overall positive correlation between the two variables $(r=0.525, p<0.001)$ [116]. Furthermore, they were able to illustrate limited but compelling evidence that improvements in gender inequality can lead to the abatement of generalized HIV epidemics in countries with predominantly heterosexual transmission. Additionally, a study on reproductive health in 75 countries revealed that the empowerment of women was associated with the improvement of several health factors, including but not limited to fertility, maternal mortality, and low birth weight of the infant [117].

\section{Limitations of the study}

The literature review aimed to collect all available data on the prevalence and predictors of female sexual dysfunction among reproductive-age women, globally. While this literature review and analysis on female sexual dysfunction covers studies from more countries than previous reviews, there were many countries which were not represented in this assessment $(n=161)$. This lack of data may be due to the fact that the search was limited to the English language or due to a lack of published research on female sexual dysfunction in these countries.

Due to the study design, a causal association between female sexual dysfunction and the reported predictors cannot be demonstrated, nor can the findings be extrapolated to the individual level. Furthermore, a quantitative analysis would be necessary in order to determine the exact effect sizes of the risk/protective factors.

Finally, while this analysis summarizes a wealth of available data on significant predictors, it simultaneously reveals a dearth of research on women's sexual health. Factors which were not documented in this analysis are not irrelevant to sexual dysfunction, i.e. a factor which was not identified in a population/group/regime does not mean it is not pertinent to that population/group/regime. More in-depth research is needed, both quantitative and qualitative, in the field of women's sexual health - particularly in regions with male-centered sexual regimes and high gender inequality.

\section{Conclusions}

The sexual and reproductive lives of women are highly impacted by female sexual dysfunction, and a number of biological, psychological and social factors play a role in the prevalence of sexual dysfunction. Healthcare professionals who work with women should be aware of the many risk factors for reproductive-age women. Future prevention strategies should aim to address modifiable factors, e.g. physical activity and access to sex education; international efforts in empowering women should continue.

\section{Additional files}

Additional file 1: Supplementary Material. Predictors by publication. (DOCX 64 kb)

Additional file 2: Supplementary Material. Significant factors stratified by sexual regime. (DOCX $22 \mathrm{~kb}$ )

Additional file 3: Supplementary Material. Significant risk factors stratified by level of human development. (DOCX $27 \mathrm{~kb}$ )

Availability of data and materials

All data generated or analyzed during this study are included in this published article. 


\section{Authors' contributions}

MMM, MAT, HK and CA were responsible for conception and design. MMM AZ, MAT and HK acquired the data. All authors were involved in analysis and interpretation. MMM, MAT and CA drafted the article. All authors gave their final approval of the article.

\section{Ethics approval and consent to participate}

Not applicable.

\section{Consent for publication}

Not applicable.

\section{Competing interests}

The authors declare that they have no competing interests.

\section{Publisher's Note}

Springer Nature remains neutral with regard to jurisdictional claims in published maps and institutional affiliations.

\section{Author details}

'Medical Sociology, Department of Epidemiology and Preventive Medicine, University of Regensburg, Dr. Gessler Strasse 17, 93051 Regensburg, Germany. ${ }^{2}$ LMU - Ludwig-Maximilians-Universität Munich, Div Metabolic and Nutritional Medicine, Dr von Hauner Children's Hospital, Univ. of Munich Medical Center, Lindwurmstr. 4, 80337 Munich, Germany. Institute of Sociology, Friedrich-Schiller-University of Jena, Fürstengraben 1, 07737 Jena, Germany. ${ }^{4}$ University Library of Regensburg, Universitaetsstrasse 3, 93053 Regensburg, Germany.

Received: 10 April 2017 Accepted: 7 June 2018

Published online: 22 June 2018

\section{References}

1. McCool ME, Zuelke A, Theurich MA, Knuettel H, Ricci C, Apfelbacher C. Prevalence of female sexual dysfunction among premenopausal women: a systematic review and meta-analysis of observational studies. Sexual Medicine Reviews. 2016;4:197-212.

2. Diagnostic and Statistical Manual of Mental Disorders. 5. Washington: American Psychiatric Association; 2013.

3. Thomas HN, Thurston RC. A biopsychosocial approach to women's sexual function and dysfunction at midlife: a narrative review. Maturitas. 2016;87: 49-60.

4. Spector IP, Carey MP. Incidence and prevalence of the sexual dysfunctions: a critical review of the empirical literature. Arch Sex Behav. 1990;19:389-408.

5. West SL, Vinikoor LC, Zolnoun D. A systematic review of the literature on female sexual dysfunction prevalence and predictors. Annu Rev Sex Res. 2004;15:40-172.

6. Nicolosi A, Laumann EO, Glasser DB, Moreira ED Jr, Paik A, Gingell C. Sexual behavior and sexual dysfunctions after age 40: the global study of sexual attitudes and behaviors. Urology. 2004;64:991-7.

7. Laumann EO, Paik A, Glasser DB, et al. A cross-national study of subjective sexual well-being among older women and men: findings from the global study of sexual attitudes and behaviors. Arch Sex Behav. 2006;35:145-61.

8. Gender Inequality Index. United Nations Development Programme; 2013.

9. [Publication search of term "Female Sexual Dysfunction"]. Web of Science Core Collection; 2016.

10. Moher D, Liberati A, Tetzlaff J, Altman DG, Group P. Preferred reporting items for systematic reviews and meta-analyses: the PRISMA statement. Open Med. 2009;3:e123-30.

11. McCool ME, Theurich MA, Apfelbacher C. Prevalence and predictors of female sexual dysfunction: a protocol for a systematic review. Systematic Rev. 2014:3:75

12. Abdo CH, Oliveira WM Jr, Moreira ED Jr, Fittipaldi JA. Prevalence of sexual dysfunctions and correlated conditions in a sample of Brazilian womenresults of the Brazilian study on sexual behavior (BSSB). Int J Impot Res. 2004;16:160-6.

13. Abdo CH, Valadares AL, Oliveira WM Jr, Scanavino MT, Afif-Abdo J. Hypoactive sexual desire disorder in a population-based study of Brazilian women: associated factors classified according to their importance. Menopause. 2010;17:1114-21.
14. Abu Ali RM, Al Hajeri RM, Khader YS, Ajlouni KM. Factors associated with sexual dysfunction in Jordanian women and their sexual attitudes. Ann Saudi Med. 2009;29:270-4.

15. Adegunloye $O A$, Makanjuola AB, Adelekan ML. Sexual dysfunction among secondary school teachers in Ilorin, Nigeria. J Sex Med. 2010;7:3835-44.

16. Aggarwal RS, Mirshra W, Panchal NA, Patel NH, Deshchougule W, Jasani AF. Sexual dysfunction in women: an overview of risk factors and prevalence in Indian women. J South Asian Feder Obst Gynae. 2012;4(3):134-6.

17. Amidu N, Owiredu WK, Woode E, et al. Incidence of sexual dysfunction: a prospective survey in Ghanaian females. Reprod Biol Endocrinol. 2010;8:106.

18. Amidu N, Owiredu WK, Gyasi-Sarpong CK, Woode E, Quaye L. Sexual dysfunction among married couples living in Kumasi metropolis, Ghana. BMC Urol. 2011:11:3.

19. Arasteh M, Alizadeh NS, Ghaderi E, Farhadifar F, Nabati R, Gharibi F. Survey of the prevalence of sexual dysfunctions in Kurdish women. J Sex Marital Therapy. 2014;40(6):503-11.

20. Aslan E, Beji NK, Gungor I, Kadioglu A, Dikencik BK. Prevalence and risk factors for low sexual function in women: a study of 1,009 women in an outpatient clinic of a university hospital in Istanbul. J Sex Med. 2008:5:2044-52

21. Avellanet YR, Ortiz AP, Pando JR, Romaguera J. Relationship between loss of libido and signs and symptoms of depression in a sample of Puerto Rican middle-aged women. P R Health Sci J. 2008;27:85-91.

22. Avellanet $\mathrm{YR}$, Ortiz AP, Pando JR, Romaguera J. Dyspareunia in Puerto Rican middle-aged women. Menopause. 2009;16:742-7.

23. Bagherzadeh $\mathrm{R}$, Zahmatkeshan N, Gharibi T, et al. Prevalence of female sexual dysfunction and related factors for under treatment in Bushehrian women of Iran. Sex Disabil. 2010;28:39-49.

24. Berglund AL, Nigaard L, Rylander E. Vulvar pain, sexual behavior and genital infections in a young population: a pilot study. Acta Obstet Gynecol Scand. 2002:81:738-42.

25. Berra M, De Musso F, Matteucci C, et al. The impairment of sexual function is less distressing for menopausal than for premenopausal women. J Sex Med. 2010;7:1209-15.

26. Beutel ME, Stobel-Richter Y, Brahler E. Sexual desire and sexual activity of men and women across their lifespans: results from a representative German community survey. BJU Int. 2008;101:76-82.

27. Blumel JE, Chedraui P, Baron G, et al. Sexual dysfunction in middle-aged women: a multicenter Latin American study using the female sexual function index. Menopause. 2009;16:1139-48.

28. Bodenmann G, Ledermann T, Blattner D, Galluzzo C. Associations among everyday stress, critical life events, and sexual problems. J Nerv Ment Dis. 2006;194:494-501.

29. Botros SM, Abramov Y, Miller JJ, et al. Effect of parity on sexual function: an identical twin study. Obstet Gynecol. 2006;107:765-70.

30. Burri A, Spector T. Recent and lifelong sexual dysfunction in a female UK population sample: prevalence and risk factors. J Sex Med. 2011:8:2420-30.

31. Cain VS, Johannes CB, Avis NE, et al. Sexual functioning and practices in a multi-ethnic study of midlife women: baseline results from SWAN. Journal Sex Res. 2003:40:266-76.

32. Castelo-Branco C, Blumel JE, Araya $\mathrm{H}$, et al. Prevalence of sexual dysfunction in a cohort of middle-aged women: influences of menopause and hormone replacement therapy. J Obstet Gynaecology. 2003;23:426-30.

33. Cayan S, Akbay E, Bozlu M, Canpolat B, Acar D, Ulusoy E. The prevalence of female sexual dysfunction and potential risk factors that may impair sexual function in Turkish women. Urol Int. 2004;72:52-7.

34. Christensen BS, Gronbaek M, Osler M, Pedersen BV, Graugaard C, Frisch M. Sexual dysfunctions and difficulties in Denmark: prevalence and associated sociodemographic factors. Arch Sex Behav. 2011;40:121-32.

35. Danielsson I, Sjoberg I, Stenlund H, Wikman M. Prevalence and incidence of prolonged and severe dyspareunia in women: results from a population study. Scand J Public Health. 2003;31:113-8.

36. Echeverry MC, Arango A, Castro B, Raigosa G. Study of the prevalence of female sexual dysfunction in sexually active women 18 to 40 years of age in Medellin, Colombia. J Sex Med. 2010;7:2663-9.

37. Elmerstig E, Wijma B, Swahnberg K. Young Swedish women's experience of pain and discomfort during sexual intercourse. Acta Obstet Gynecol Scand. 2009;88:98-103

38. Elnashar A, Abdelhady R. The impact of female genital cutting on health of newly married women. Int J Gynaecol Obstet. 2007;97:238-44.

39. Elnashar AM, El-Dien Ibrahim M, El-Desoky MM, Ali OM, El-Sayd Mohamed Hassan M. Female sexual dysfunction in lower Egypt. BJOG. 2007;114:201-6. 
40. Elsamra S, Nazmy M, Shin D, Fisch H, Sawczuk I, Fromer D. Female sexual dysfunction in urological patients: findings from a major metropolitan area in the USA. BJU Int. 2010;106:524-6.

41. Eplov L, Giraldi A, Davidsen M, Garde K, Kamper-Jorgensen F. Sexual desire in a nationally representative Danish population. J Sex Med. 2007;4:47-56.

42. Erbil N. Prevalence and risk factors for female sexual dysfunction among Turkish women attending a maternity and gynecology outpatient clinic. Sex Disabil. 2011;29:377-86

43. Evangelia N, Kirana PS, Chiu G, Link C, Rosen R, Hatzichristou D. Level of bother and treatment-seeking predictors among male and female in-patients with sexual problems: a hospital-based study. J Sex Med. 2010;7:700-11.

44. Fajewonyomi BA, Orji EO, Adeyemo AO. Sexual dysfunction among female patients of reproductive age in a hospital setting in Nigeria. J Health Popul Nutr. 2007;25:101-6.

45. Ferenidou F, Kapoteli V, Moisidis K, Koutsogiannis I, Giakoumelos A, Hatzichristou D. Presence of a sexual problem may not affect women's satisfaction from their sexual function. J Sex Med. 2008:5:631-9.

46. Garcia-Perez H, Harlow SD, Erdmann CA, Denman C. Pelvic pain and associated characteristics among women in northern Mexico. Int Perspect Sex Reprod Health. 2010;36:90-8.

47. Ghanbarzadeh N, Nadjafi-Semnani M, Ghanbarzadeh MR, Nadjfai-Semnani A, Nadjfai-Semnani F. Female sexual dysfunction in Iran: study of prevalence and risk factors. Arch Gynecol Obstet. 2013;287:533-9.

48. Goshtasebi A, Vahdaninia M, Rahimi Foroshani A. Prevalence and potential risk factors of female sexual difficulties: an urban Iranian population-based study. J Sex Med. 2009;6:2988-96.

49. Graziottin A. Prevalence and evaluation of sexual health problems-HSDD in Europe. J Sex Med. 2007;4(Suppl 3):211-9.

50. Grewal GS, Gill JS, Sidi H, Gurpreet K, Jambunathan ST, Suffee NJ. Sexual desire disorder in female healthcare personnel in Malaysia. Asia Pac Psychiatry. 2013;5(Suppl 1):14-20.

51. Hamilton L, Kulseng-Berg A, Traeen B, Lundin-Kvalem I. Self-reported frequency of feeling sexual desire among a representative sample of 18-49year-old men and women in Oslo. Scand J Sex. 2001;4:25-41.

52. Hassanin IM, Helmy YA, Fathalla MM, Shahin AY. Prevalence and characteristics of female sexual dysfunction in a sample of women from upper Egypt. Int J Gynaecol Obstet. 2010;108:219-23.

53. Hayes RD, Dennerstein L, Bennett CM, Sidat M, Gurrin LC, Fairley CK. Risk factors for female sexual dysfunction in the general population: exploring factors associated with low sexual function and sexual distress. J Sex Med. 2008;5:1681-93.

54. Hisasue S, Kumamoto Y, Sato Y, et al. Prevalence of female sexual dysfunction symptoms and its relationship to quality of life: a Japanese female cohort study. Urology. 2005;65:143-8.

55. Ibrahim ZM, Ahmed MR, Sayed Ahmed WA. Prevalence and risk factors for female sexual dysfunction among Egyptian women. Arch Gynecol Obstet. 2013;287:1173-80

56. Ishak $1 \mathrm{H}$, Low WY, Othman S. Prevalence, risk factors, and predictors of female sexual dysfunction in a primary care setting: a survey finding. I Sex Med. 2010;7:3080-7.

57. Jaafarpour M, Khani A, Khajavikhan J, Suhrabi Z. Female sexual dysfunction: prevalence and risk factors. J Clin Diagn Res. 2013;7:2877-80.

58. Jahan MS, Billah SM, Furuya H, Watanabe T. Female sexual dysfunction: facts and factors among gynecology outpatients. J Obstet Gynaecol Res. 2012;38: 329-35.

59. Jiann BP, Su CC, Yu CC, Wu TT, Huang JK. Risk factors for individual domains of female sexual function. J Sex Med. 2009;6:3364-75.

60. Klusmann D. Sexual motivation and the duration of partnership. Arch Sex Behav. 2002;31:275-87.

61. Lau JT, Kim JH, Tsui HY. Prevalence of male and female sexual problems, perceptions related to sex and association with quality of life in a Chinese population: a population-based study. Int J Impot Res. 2005;17:494-505.

62. Lau JT, Cheng Y, Wang Q, Yang X. Prevalence and correlates of sexual dysfunction among young adult married women in rural China: a population-based study. Int J Impot Res. 2006;18:89-97.

63. Leiblum SR, Koochaki PE, Rodenberg CA, Barton IP, Rosen RC. Hypoactive sexua desire disorder in postmenopausal women: US results from the Women's international study of health and sexuality (WISHeS). Menopause. 2006;13:46-56.

64. Lianjun P, Aixia Z, Zhong W, Feng P, Li B, Xiaona Y. Risk factors for low sexual function among urban Chinese women: a hospital-based investigation. J Sex Med. 2011;8:2299-304.
65. Lo SS, Kok WM. Sexual behavior and symptoms among reproductive age Chinese women in Hong Kong. J Sex Med. 2014;11:1749-56.

66. Lutfey KE, Link CL, Rosen RC, Wiegel M, McKinlay JB. Prevalence and correlates of sexual activity and function in women: results from the Boston area community health (BACH) survey. Arch Sex Behav. 2009;38:514-27.

67. Mitchell KR, Mercer CH, Ploubidis GB, et al. Sexual function in Britain: findings from the third National Survey of sexual attitudes and lifestyles (Natsal-3). Lancet. 2013;382:1817-29.

68. Mitchell KR, Mercer CH, Wellings K, Johnson AM. Prevalence of low sexual desire among women in Britain: associated factors. J Sex Med. 2009;6: 2434-44.

69. Najafabady MT, Salmani Z, Abedi P. Prevalence and related factors for anorgasmia among reproductive aged women in Hesarak, Iran. Clinics. 2011;66:83-6.

70. Nappi RE, Albani F, Vaccaro $P$, et al. Use of the Italian translation of the female sexual function index (FSFI) in routine gynecological practice. Gynecol Endocrinol. 2008:24:214-9.

71. Nazareth I, Boynton P, King M. Problems with sexual function in people attending London general practitioners: cross sectional study. BMJ. 2003; 327:423.

72. Ojanlatva A, Helenius H, Jokinen K, Sundell J, Makinen J, Rautava P. Sexual activity and background variables among Finnish middle-aged women. Am $J$ Health Behav. 2004;28:302-15.

73. Ojomu F, Thacher T, Obadofin M. Sexual problems among married Nigerian women. Int J Impot Res. 2007;19:310-6.

74. Oksuz E, Malhan S. Prevalence and risk factors for female sexual dysfunction in Turkish women. J Urol. 2006;175:654-8. discussion 58

75. Oniz A, Keskinoglu P, Bezircioglu I. The prevalence and causes of sexual problems among premenopausal Turkish women. J Sex Med. 2007:4:1575-81.

76. Padmadas SS, Stones RW, Matthews Z. Dyspareunia and urinary sensory symptoms in India: population-based study. J Sex Med. 2006;3:114-20.

77. Parish WL, Laumann EO, Pan S, Hao Y. Sexual dysfunctions in urban China: a population-based national survey of men and women. J Sex Med. 2007:4: 1559-74.

78. Peixoto MM, Nobre P. Prevalence and Sociodemographic predictors of sexual problems in Portugal: a population-based study with women aged 18 to 79 years. J Sex Marital Therapy. 2015;41(2):169-80.

79. Peixoto MM, Nobre P. Prevalence of sexual problems and associated distress among lesbian and heterosexualwomen. J Sex Marital Ther. 2015:41(4):427-39.

80. Pereira VM, Nardi AE, Silva AC. Sexual dysfunction, depression, and anxiety in young women according to relationship status: an online survey. Trends Psychiatry Psychother. 2013;35:55-61.

81. Ponholzer A, Roehlich M, Racz U, Temml C, Madersbacher S. Female sexual dysfunction in a healthy Austrian cohort: prevalence and risk factors. Eur Urol. 2005;47:366-74. discussion 74-5

82. Reed BD, Crawford S, Couper M, Cave C, Haefner HK. Pain at the vulvar vestibule: a web-based survey. J low Genit Tract Dis. 2004;8:48-57.

83. Richters J, Grulich AE, de Visser RO, Smith AM, Rissel CE. Sex in Australia: sexual difficulties in a representative sample of adults. Aust N Z J Public Health. 2003;27:164-70.

84. Safarinejad MR. Female sexual dysfunction in a population-based study in Iran: prevalence and associated risk factors. Int J Impot Res. 2006;18:382-95.

85. Sanders SA, Graham CA, Milhausen RR. Predicting sexual problems in women: the relevance of sexual excitation and sexual inhibition. Arch Sex Behav. 2008;37:241-51.

86. Shaeer O, Shaeer K. The global online sexuality survey (GOSS): erectile dysfunction among Arabic-speaking internet users in the Middle East. J Sex Med. 2011;8:2152-60. quiz 60-3

87. Shifren JL, Monz BU, Russo PA, Segreti A, Johannes CB. Sexual problems and distress in United States women: prevalence and correlates. Obstet Gynecol. 2008;112:970-8.

88. Shindel AW, Rowen TS, Lin TC, Li CS, Robertson PA, Breyer BN. An internet survey of demographic and health factors associated with risk of sexual dysfunction in women who have sex with women. J Sex Med. 2012;9:1261-71.

89. Sidi H, Puteh SE, Abdullah N, Midin M. The prevalence of sexual dysfunction and potential risk factors that may impair sexual function in Malaysian women. J Sex Med. 2007:4:311-21.

90. Singh JC, Tharyan P, Kekre NS, Singh G, Gopalakrishnan G. Prevalence and risk factors for female sexual dysfunction in women attending a medical clinic in South India. J Postgrad Med. 2009;55:113-20. 
91. Sobhgol SS, Alizadeli Charndabee SM. Rate and related factors of dyspareunia in reproductive age women: a cross-sectional study. Int J Impot Res. 2007;19:88-94.

92. Song $\mathrm{SH}$, Jeon $\mathrm{H}$, Kim SW, Paick JS, Son $\mathrm{H}$. The prevalence and risk factors of female sexual dysfunction in young korean women: an internet-based survey. J Sex Med. 2008;5:1694-701.

93. Stones RW, Padmadas SS, Guo S, Brown JJ, Zhao F, Li B. Dyspareunia, urinary sensory symptoms, and incontinence among young Chinese women. Arch Sex Behav. 2006;35:561-7.

94. Stulhofer A, Gregurovic M, Pikic A, Galic I. Sexual problems of urban women in Croatia: prevalence and correlates in a community sample. Croatian Med J. 2005;46:45-51.

95. Stulhofer A, Kuljanic K, Buzina DS. Sexual health difficulties in a population-based sample of Croatian women aged 18-35 and the effects of the dual (career and motherhood) role. J Sex Med. 2011;8: 1314-21.

96. Sznajder KK, Harlow SD, Burgard SA, Wang Y, Han C, Liu J. Gynecologic pain related to occupational stress among female factory workers in Tianjin, China. Int J Occup Environ Health. 2014;20:33-45.

97. Tracy JK, Junginger J. Correlates of lesbian sexual functioning. J Women's Health. 2007;16:499-509.

98. Træen B, Martinussen M, Öberg K, Kavli H. Reduced sexual desire in a random sample of Norwegian couples. Sex Relationship Therapy. 2007;22: 303-22.

99. Vahdaninia M, Montazeri A, Goshtasebi A. Help-seeking behaviors for female sexual dysfunction: a cross sectional study from Iran. BMC Womens Health. 2009;9:3.

100. Valadares AL, Pinto-Neto AM, Osis MJ, Sousa MH, Costa-Paiva L, Conde DM. Prevalence of sexual dysfunction and its associated factors in women aged 40-65 years with 11 years or more of formal education: a population-based household survey. Clinics. 2008;63:775-82.

101. Vanwesenbeeck I, Bakker F, Gesell S. Sexual health in the Netherlands: main results of a population survey among Dutch adults. Int J Sex Health. 2010; 22:55-71.

102. Varghese KM, Bansal R, Kekre AN, Jacob KS. Sexual dysfunction among young married women in southern India. Int Urogynecol J. 2012;23:1771-4.

103. Villeda Sandoval Cl, Calao-Perez M, Enriquez Gonzalez AB, et al. Orgasmic dysfunction: prevalence and risk factors from a cohort of young females in Mexico. J Sex Med. 2014;11:1505-11.

104. Wallwiener CW, Wallwiener LM, Seeger H, Muck AO, Bitzer J, Wallwiener M. Prevalence of sexual dysfunction and impact of contraception in female German medical students. J Sex Med. 2010;7:2139-48.

105. Weiss P, Brody S. Female sexual arousal disorder with and without a distress criterion: prevalence and correlates in a representative Czech sample. J Sex Med. 2009;6:3385-94.

106. Witting K, Santtila P, Varjonen M, et al. Female sexual dysfunction, sexual distress, and compatibility with partner. J Sex Med. 2008;5:2587-99.

107. Worly B, Gopal M, Arya L. Sexual dysfunction among women of low-income status in an urban setting. Int J Gynaecol Obstet. 2010;111:241-4.

108. Yanez D, Castelo-Branco C, Hidalgo LA, Chedraui PA. Sexual dysfunction and related risk factors in a cohort of middle-aged Ecuadorian women. J Obstet Gynaecol. 2006;26:682-6.

109. Zhang $H$, Yip PS. Female sexual dysfunction among young and middleaged women in Hong Kong: prevalence and risk factors. J Sex Med. 2012;9: 2911-8

110. Parish WL, Luo Y, Stolzenberg R, Laumann EO, Farrer G, Pan S. Sexual practices and sexual satisfaction: a population based study of Chinese urban adults. Arch Sex Behav. 2007;36:5-20.

111. Choi H, Kim JH, Park JY, et al. Assessment of sexual dysfunction and determination of its risk factors in the Republic of Korea. Int J Gynaecol Obstet. 2014;125:60-4

112. Basson R, Berman J, Burnett $A$, et al. Report of the international consensus development conference on female sexual dysfunction: definitions and classifications. J Urol. 2000;163:888-93.

113. Hayes RD, Dennerstein L, Bennett CM, Koochaki PE, Leiblum SR, Graziottin A. Relationship between hypoactive sexual desire disorder and aging. Fertil Steril. 2007;87:107-12.

114. MDG 3: promote gender equality and empower women. In: Organization WH, ed.; 2015
115. Mechakra-Tahiri SD, Freeman EE, Haddad S, Samson E, Zunzunegui MV. The gender gap in mobility: a global cross-sectional study. BMC Public Health. 2012;12:598

116. Richardson ET, Collins SE, Kung T, et al. Gender inequality and HIV transmission: a global analysis. J Int AIDS Soc. 2014;17:19035.

117. Varkey P, Mbbs KS, Lesnick T. Empowerment of women and its association with the health of the community. J Women's Health. 2010;19:71-6.

\section{Ready to submit your research? Choose BMC and benefit from:}

- fast, convenient online submission

- thorough peer review by experienced researchers in your field

- rapid publication on acceptance

- support for research data, including large and complex data types

- gold Open Access which fosters wider collaboration and increased citations

- maximum visibility for your research: over $100 \mathrm{M}$ website views per year

At BMC, research is always in progress.

Learn more biomedcentral.com/submissions 